\title{
IKEA's Challenges and Opportunities In Asia
}

\author{
Benjamin Etukudoh ${ }^{1}$ and Esther Joe - Daniel Joe ${ }^{2}$ \\ ${ }^{1}$ University of Nicosia \\ ${ }^{2}$ Affiliation not available
}

April 28, 2020

\section{Introduction.}

Large organizations like IKEA would equally face challenges like those faced by smaller market players especially when attempting to penetrate new markets. More so when the language, culture and legal requirements are very different from where she comes from or origin. The opportunities and challenges in the new country determine managerial and marketing strategies that must be employed by any company on the growth journey.

In the sections that follow, first, an attempt is made to analyze the opportunities and challenges for IKEA in their market operations in China, an emerging market as well as Japan which was a more advanced economy. The entry strategies are also being analyzed, key considerations and strategies for market entries are presented. IKEA's product, pricing, marketing communication and distribution decisions and how the selected options addressed the identified challenges is discussed.

Finally, my opinion on what would be IKEA's marketing strategy in future in order to gain and sustain market shares thereby increasing shareholder value is presented.

\section{Opportunities and Challenges in China}

The case study mentioned far Asia an emerging market. Emerging markets in the infant stage would typically be characterized by rapid growth. Leaders in power in such countries are usually willing to undertake rapid changes to lunch them into an industrialized economy KIMBERLY AMADEO - What Are Emerging Markets? Five Defining Characteristics.

First, these countries are characterized by low wages. The workforce in these countries would typically have wages in the region of $\$ 4,035$. . The low wages are for sure an incentive for international brands like IKEA. Compared to wages, for equivalent services in Europe, this is very low really fits IKEA's strategies to keep production cost low. Sourcing local material and Production in China would have been to for export would have been considered low at that time. The government of the day would have been very open to foreign investments to remain in power, help its citizen and promote rapid economic growth.

Another opportunity IKEA would have seen is the rapid social changes that come with the rising Average Per Capita Income of countries in this economic phase of an emerging market. The citizens are then able to buy more even at relatively higher prices. This provides abundant business opportunities as the middle class with higher income expands. This is evident as most of IKEA's Customers are in the age bracket of 20-35 years. 
Seeing an emerging economy that was in its infant stage, IKEA would have seen an opportunity in quickly establishing self as the dominant international brand providing modern western style furniture. It would have been more difficult for IKEA to buy consumer loyalty if it must compete with other internationals in the same market.

Despite all the opportunities the emerging economy status of China presented, IKEA's entry in that market was not a bed of roses.

First, it was the challenges of breaking even, despite recorded large volumes of sale as the majority of the sales where small decoration items with very low-profit margins. They had more people visiting the stores than those who made actual purchases. This challenge suggested that IKEA's selection of products is probably not appealing to the Chinese.

Product price competitiveness was another area of the challenge faced by the Scandinavian furniture giant. This was particularly unique for IKEA because she derived her price competitiveness in the developed markets by sourcing raw material and production, outsourced from developing countries like China and Malaysia. This low-price strategy that worked in the European market obviously was not a plausible one for the Chinese market because the medium and low-income Chinese consumer found the local brands more affordable at the time. Local manufacturers, who are not concerned with quality products would go as far as imitating IKEA's products style for lower prices. This situation no doubt further compounded IKEA's challenge with price competitiveness.

Worthy of note was the unpopularity of IKEA's DIY concepts with the Chinese for home furnishing, further compounded by the already perceived high pricing. The Chinese consumers are used to the accompanying delivery and assembly services for furniture.

\section{Opportunities and Challenges in Japan}

IKEA did not have an easy entry into the Japanese market. This would be typical of new businesses trying to enter into already established markets. Japan has been evaluated to be the world's second-largest economy for the most part of the last four decades following the United States. After successfully entering, neighbouring European countries, IKEA took its internationalization drive to Asia Japan.

During and post the second world war era in that started in 1973, after the Arab oil embargo Japan went into a severe recession, characterized by an increase in raw material cost, the decline in private investment resulting in declining economic growth from the 10\% levels to an average of 3.6\% during the period 1974-1979.

. Recession can present excellent opportunities for investments as asset prices are low, as investors are forced to dump their business, shrewd businessmen can pick up these businesses for a fraction of the cost prior to the recession.. IKEA would have seen opportunities even in this situation of a severe recession. IKEA Japan CEO said, "We opened because Japan is the second-biggest economy and retail market in the world.". Just after the recession, Japan like China would have become very attractive to foreign investments as the country will experience rapid economic growth. The growing population often associated with economic growth would have presented opportunities for IKEA.

Since Ikea was not successful in its first attempt to enter the Japanese market, IKEA made a second attempt in 2006. This decision would have come after gathering more experience from its other international expansions like the USA in 1985, Canada in 1976, China in 1998 etc. The furniture giant would have also seen opportunities in the deregulation of Japan's retail market that was launched in response to the Structural Impediments Initiative (SII) in 1989. This led to the enactment of the Large-Scale Retail Store Location Law for retail businesses, in June 2000. This law saw more foreign businesses entering Japan's retail markets. These companies are now able to adopt the "Go-It-Alone" Strategy, as opposed to franchise or the partnership approach. 


\section{Market Entry Strategy}

A market entry strategy is a way an organization chooses to enter a new market. Allison Tanner in his lecture on Market entry considers the decision of whether the organization is expanding domestically or internationally to be the first point of consideration. This is important as expansion domestically will have different requirements from when considering international expansion. Among other factors that may impact how the company integrates into the new market, are:

- Type of industry

- Agility of the products

- The culture of the new market

- Costs associated with entering a new market

- Local and international laws of importation and exportation

From the IKEA case study, the factors mentioned above had some impact on the decisions and the resulting strategy that was adopted. Many organizations choose between the low-cost, limited-commitment strategies of entering and developing overseas markets, and the high-investment, high-goal strategies. The choices made usually will represent a measure of the company's risk appetite.

The following the entry strategies are considered a low-risk entry modeIndirect Exporting - This is where the company sell its product to an intermediary who then makes it available to the end-users or resells to other importers. Whereas Direct Exporting will offer more control. It involves selling directly to end-users in an international market. Irrespective of the involvement of intermediaries, this mode of market entry can still be considered Direct export when the intermediary itself is the target market. Licensing is when foreign firms can use patents, trademark, designs or copyrights for a fee.

The more aggressive organizations, ambitious for greater control and wish to leverage external experience and capital may consider theJoint Venture Strategy. This is a popular market entry mode where two or more parties come together by way of shared ownership, profits, risk and governance. The Direct Investment mode can take either of two forms; Green Field Investment andAcquisitions . Both give the company better control with great potential; however, it can come at a higher risk.

Because markets differ; and every market has different needs, modus operandi and buying patterns. Therefore, there is no one strategy to fit all philosophy.

IKEA entered mainland china 1998 and opened its first store in Shanghai, and immediately followed with a second one in Beijing only a year later. These two stores were opened in a Joint Venture strategy. IKEA took five years to study the Chinese market before opening its first full-scale standard Shop in Shanghai in 2003. This was the largest of its store in Asia. The reference material for this work described this entry as a prudent approach. The approach enabled the European home furniture giant to further understand the local needs of the Chinese consumers and fine-tuned its strategy. The company made several changes to its product line. It learnt that the Chinese apartments were small so the consumers would prefer modular solutions, they even went as far as adjusting the physical layout of its stores to reflect the typical Chinese apartments and included balconies. . IKEA may have considered this strategy based on its experience from entry into the other Asian and international markets. For instance, when they entered the US market, American consumers demanded bigger sized beds and closets, and the company had to adjust product styles in order to become appealing to the US market.

In Japan, IKEA adopted the same Joint Venture approach to enter Japan in 1974. This entry was however not a success, as the Sweden-based furniture giant was not able to establish her presence significantly in the Japanese market. Exited in 1986 and spent 5 years to further study the markets. It came back in 2006, this time with a different strategy. It now opened her two fully owned outlets in Funabashi (Tokyo) and Kohoku. By 2008, she has opened two more in Kobe and Osaka. These stores were large, occupying 40,000 square meters with an indoor restaurant that could seat over 700 people. This time the Scandinavian furniture giant adopted the more aggressive Direct Investment strategy. No wonder IKEA Japan K.K. President 
and CEO Tommy Kullberg agreed the company made a mistake in its first entry but has learned from these mistakes. The results from the study conducted reveal that size is the key to the company's success. He said, "We saw hundreds of houses to figure out how you take a bath, how you cook, how you sleep and how you store things, we drew a conclusion that our contribution will help Japan when it comes to sizes." He agreed that the Japanese market was really demanding, and the consumers never liked and were not ready for the do-it-yourself style.

\section{The product, pricing, marketing communication and Distribution Strategies.}

The marketing mix is operating decisions an organization uses to achieve its marking objective. These decisions border around the Products, Pricing, Promotion or marketing communication and Positioning or Distribution. The major considerations that influence an organizations choice in the marketing mix are:

- Strategic objective

- Focus

- Customer targets

- Competitor targets

- Core strategy

The products of an organization are the goods and services the business offers to the consumers. It is best defined in terms of itsBreadth, referring to the number of different product line a company carries. The Length is the volume of products within a line of product and the Depth as the variations that exist within the product line.. By way of analysis, in terms of thebreadth, IKEA offers a one-stop shop for all you need for functional home furnishing, for instance, her products range from items for gardens, kitchens, children rooms and toys, living-room etc. In addition, these items come in a variety of style; in IKEA shops you find products for the aristocrats as much as you will find for the minimalist. And in terms of the length, you are guaranteed the quantities of any of product as you need. They also offered a product that had some cultural essence in both China and Japan.

Based on IKEA's Strategic Objective driven by its Vision statement "To Create A Better Everyday Life for the People". The company has consistently pursued its Customer Targets objective by offering a wide range of products that are well-designed, functional and widely affordable by as many as possible. In meeting the objective of creating a better everyday life for people, they haveFocused on making products that symbolize the home as the most important place in the world. .

According to , the more ambitious the growth objective of an organization is, the bigger the breadth, Length and Depth of its product mix. No wonder IKEA's first shop in Mainland China held more than 7,000 different lines of product with value-added services of providing 170 square meters of children's playground accompanied by free parking to hold 800 cars. The same approach was used in her second missionary journey to Japan when the Scandinavian furniture mogul, in 2006 abandoned the Joint Venture strategy and launched two IKEA-own outlets, occupying a space of over 40,000 Square meters. This grand entrance signified its ambition to dominate the markets and put her products at the reach of as many as possible. Just to appeal to the consumers, IKEA would release a series of products to celebrate the Chinese New Year. IKEA Japan's retail manager, Lars Petersson said that the company did not change the sizes of its products in Japan, rather it selected 7,500 out of its 10,000-Line of products that was particularly suited for the Japanese homes. This strategy helped to avoid the additional cost that would have been associated with changing product sizes in order to make the furniture appeal to the Japanese consumers rather it delivered only those products that met the consumer's needs.

Pricing is another very critical factor that can influence the growth of an organization as pricing is the element of the marking mix that is directly related to revenue; every other element escalates the cost. Again, 
the company's decision on prices are based on the same organization's strategic objectives listed above. Internationalization would mean that competitive product pricing in one country may not be in another. This was not different for IKEA in China and Japan. As its strategy for cost advantage in Sweden, would not be a plausible one in China. In China, locally made furniture where cheaper, largely because the local producers do not invest in quality design, and sometimes imitate designs of the popular foreign brands include those of IKEA. In China, IKEA reduced its prices by about $12 \%$ in 2002, That strategy attracted more customers. Today, IKEA has launched a strategy named "The Lowest Price in Beijing". This strategy is expected to deliver prices $20 \%$ less than those of its competitors.

IKEA has a corporate strategy to design the price tag first and then make products that suite the price. - Implementation of highly cost-efficient production systems combined with very strict financial discipline, for instance, Kamprad, the CEO and founder of IKEA flies economy class and uses the public transportation for business trips produces furniture at the startlingly low process by the Japanese standards.. The company adopts cost-efficient production processes by way of Recycling; sorting every recyclable material including returns from customers. Placing products not suitable to sell at full price are offered for sales AS-IS , thereby generating from what could have as well been discarded. Securing long term contracts with manufacturers and supplier with the aim to benefit from theEconomic of Scale by negotiation reduced cost due to demanding raw material in bulk. The company also ensures providers of raw materials are near the source and in low-cost countries.

Marking Communication strategy entails all decision that covers, advertising, public relations, sale promotion including online techniques etc. A key decision for the business manager here is the choice of the message the organization intend to pass on consumers. Building the brand as quickly as possible in anticipation of future competition was IKEA's strategy in China and Japan. This approach will require an appreciable level of promotional spend. The choice of the options must be tailored to suit the Target Customer, as IKEA's most important target group is families with children that must have informed the decision to invest in large size children playground and food section with an appreciable seating capacity in all its stores for their relatively young ( $30 \mathrm{~s})$ population that formed a major segment of the customer's age distribution. IKEA's also invested in reasonably conspicuous showrooms with its distinctive yellow and blue logo hung up high in the buildings. They designed the store layout and presented the furniture in a near real home fashion that appeals to the consumers. IKEA also attempts to pride self as an organization with superlative abilities in interior decorations by offering to help customers with their design needs as opposed to only selling products at low prices.

The distribution decisions are those, required to place the products within the reach of the consumer. As with the rest of the market mix elements, channel decision should reflect the organization's overall objectives. Whatever distribution mechanism is adopted, it should be such that it creates a differential advantage by matching consumer needs and preferences more effectively when compared with those offered by the

\section{Target Competitions}

IKEA typically locates its outlets strategically along highways and interstate routes. This enhances visibility as a strategy for product promotion as well as guarantee's easy access and. Store location considerations not only addresses customer access but proximity to distribution centers and warehouses, a cost-effective approach to logistic expenses. In Japan, IKEA built two logistics centers in Shanghai in addition to the one built in Song Jiang in 2005. The company completed yet another 3000,000 cubic meters capacity logistic centre in Feng Xian in 2010 with a quality control center. To reach most of China's population of over 1.3 Billion without good road network and private transportation, IKEA changed its corporate strategy for outlet location and situated stores in high-density parts of China. For example, its Shanghai store is situated in one of China's most expensive downtown district with access to public transportation and runs from 10 AM to 10 PM daily. 


\section{Recommendation}

From the case study and the research done to put this work together, it IKEAs travails, lessons learned and eventual success clearly proved the theory that no single strategy will fit all market. The marketing environment is one that is constantly changing the, so IKEA needs to continuously evaluate its key performance indicators for relevance in the dynamic market environment. IKEAS product and pricing strategies have been evaluated to be very effective, however, it's communications and production promotion approaches would require some modernization, especially and the light of the very paced information technology era. Its communication should accommodate both global approaches as well as localized methods.

Based on its experience, it is essential that IKEA become more flexible in its product design and continue to invest in market research in order to keep abreast with the changing cultures, customer requirements, incoming competitions and environmental dynamics. 